\title{
Erratum to: Real Estate Transactions
}

\author{
Tobias Just and Hermann Stapenhorst
}

\section{Erratum to:}

Chapter 1 in: T. Just, H. Stapenhorst (eds.), Real Estate Due Diligence, Management for Professionals, https://doi.org/10.1007/978-3-319-62510-2_1

Owing to an oversight on the part of the Springer Fig. 2 of this chapter was initially published with errors. The correct presentation is given here. 


\section{Incorrect Figure}

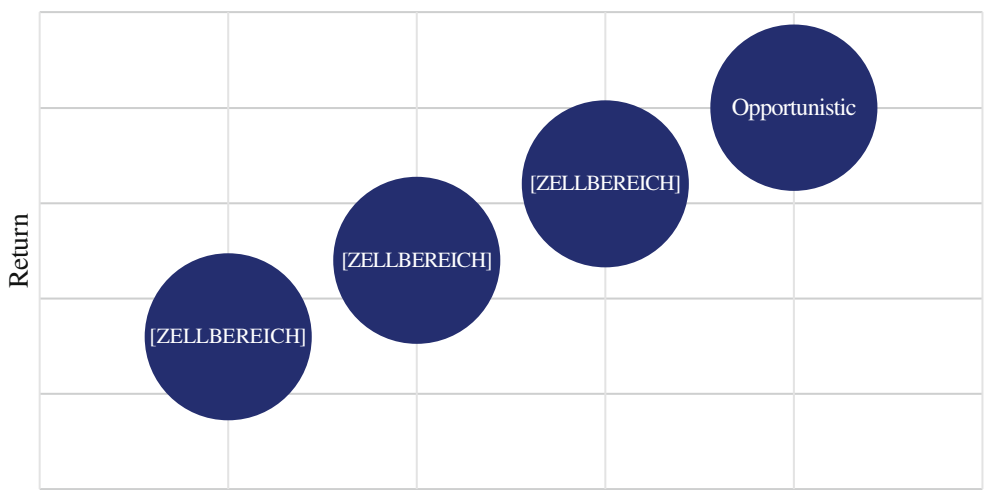

Risk

Fig. 2 The link between risk and return. Source: own depiction

\section{Correct Figure}

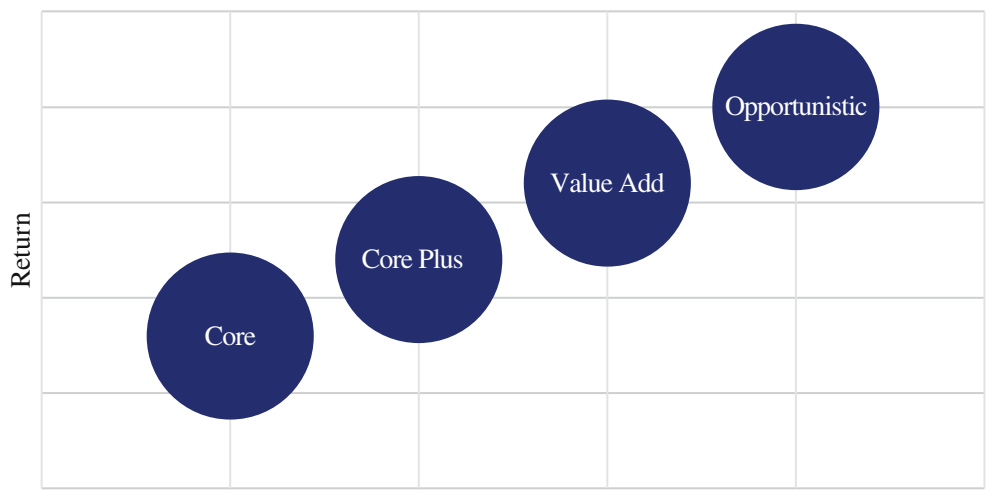

Risk

Fig. 2 The link between risk and return. Source: own depiction 